\title{
Spontaneous Vaginal Delivery of an Average Sized Dead Baby with Hand Prolapse at Term: A Case Report
}

\author{
Samjhana Dhakal.
}

Maternity Hospital, Thapathali, Kathmandu,Nepal

\begin{abstract}
Inspite of chances of rupture of the uterus in transeverse lie with hand prolapse in a 30 year old G3P2L2 at term pregnancy vaginal delivery occurred spontaneously in operation table with a small rent in the posterior vaginal fornix as a minor complication, a rare occurrence which is reported for the general public interest.
\end{abstract}

Key words: Hand prolapse, vaginal delivery, rent

\section{Introduction}

In a transverse lie, the fetus lies generally with the cephalic pole in one or other side of the iliac fossa and the breech at the opposite end. Incidence is 1/200. ${ }^{1}$ It is more common in multipara than in primipara resulting more often in premature labour than at term.

Causes of transverse lie are contracted pelvis, placenta praevia, tumors complicating pregnancy, multiparity, hydramnios and uterine anomalies. Multiple pregnancy, pendulous abdomen \& prematurity also predispose to malpresentation. $^{2}$

There are 4 positions dorso anterior, dorso posterior,dorso superior, dorso inferior and acromio anterior. Denominators are dorsum and acromian process. During labour transverse lie may deliver spontaneously by itself in a very few exceptional cases either by spontaneous rectification as vertex or spontaneous version as breech. Spontaneous evolution is the one where there is expulsion of breech and trunk followed by head. In spontaneous expulsion that is corpore conduplicate the fetus comes out in double up position. This is possible when baby is small dead or macerated which is described in this case report. ${ }^{3}$

\section{Case}

A 30 year old had come to the emergency room of Maternity Hospital on July 2008 with complaints of pain abdomen for 2 days, leaking of water per vagina and hand prolapse for 1 day. She was G3P2L2 at term with hand prolapse in labour. After the general and physical examination, she was prepared for emergency LSCS in view of hand prolapse. She was shifted to the operation theatre and was transferred to operation table. As Anaesthetist was preparing for spinal anaesthesia, suddenly she started pushing and delivered a macerated dead fetus in a doubled up manner that weighed 2.6 $\mathrm{kg}$. Placenta and the membrane was removed by CCT. After completion of delivery, exploration revealed a small rent of about $3 \mathrm{~cm}$ in posterior vaginal fornix in pouch of Douglas (POD) whereas uterus, cervix, and vulva, all were intact. The rent was repaired with chromic catgut nol. Higher antibiotics were started. Patient was in the hospital for 7 days. Postnatal period was uneventful. She was discharged on D8 of vaginal delivery. After 6 weeks she came for postnatal checkup.

\section{Comment}

Spontaneous expulsion that is corpora conduplicata is a rare way of fetal expulsion in transverse lie which 
may occur when the baby is small or macerated ${ }^{2}$. In this case the baby was macerated but weight was 2.6 $\mathrm{kg}$, which was average weight for Nepalese women, yet the delivery was possible vaginally.

One of the complications of transverse lie in labour is rupture of the uterus, because of obstructed labour in multiparous women. ${ }^{3}$ But in this case despite of prolonged labour and average size of the baby with hand prolapse, there were no signs of obstructed labour like Bandles ring complicating to uterine rupture, making this case interesting for reporting. ${ }^{4}$

\section{References}

1. Lawson $\mathrm{J}$.Delivery of the dead or malformed fetus. Clin Obstel Gynaecol 1982Dec; 9(3):745756

2. Anya E. Technique of vaginal delivery of a dead fetus in transverse lie with hand prolapse. Trop Doct 1999 Oct; 29(4):254.

3. Arora R, Rajaram P, Oumachigui A, Parveena. Destructive operations in modern obstetrics in a developing country at tertiary level. Br J Obstet Gynaecol. 1993 Oct; 100(10):967-8.

4. Seffah JD. Maternal and perinatal mortality and morbidity associated with transverse lie. Int J Gynaecol Obstet. 1999 Apr; 65(1): 11-5 